\title{
Original Research \\ Quantitative analysis of ecological suitability and stability of meandering rivers
}

\author{
Zicheng $\mathrm{Yu}^{1,2}$, Jing Zhang ${ }^{1,2, *}$, Hongtao Wang ${ }^{3}$, Jinyong Zhao ${ }^{1,2}$, Zheren Dong ${ }^{1,2}$, \\ Wenqi Peng ${ }^{1,2}$, Xianfu Zhao ${ }^{4}$ \\ ${ }^{1}$ State Key Laboratory of Simulation and Regulation of Water Cycle in River Basin, 100038 Beijing, China \\ ${ }^{2}$ Department of Water Ecology and Environment, China Institute of Water Resources and Hydropower Research, 100038 Beijing, China \\ ${ }^{3}$ Department of hydraulic engineering, Yellow River Conservancy Technical Institute, 475004 Kaifeng, Henan, China \\ ${ }^{4}$ Institute of Hydroecology, MWR \& CAS, 430079 Wuhan, Hubei, China \\ *Correspondence: zhangjing@gmail.com (Jing Zhang) \\ Academic Editors: Kevin Cianfaglione \\ Submitted: 15 July 2021 Revised: 21 December 2021 Accepted: 23 December 2021 Published: 24 January 2022
}

\begin{abstract}
Background: As the most widely distributed river form in the world, meandering river is of great significance for stabilizing the physical structure of the river and maintaining ecosystem. To quantitatively study the positive effects of meandering rivers, the Chishui River, a natural tributary of the Yangtze River in Southwest China, is selected as the research area, and two typical river sections with different meandering degrees are selected as the research objects. Methods: Based on the field survey data, the local endemic fish Procypris rabaudi (Tchang) is considered the object fish, and a hydrodynamic model was used to simulate the distribution of water depth and flow velocity in certain river reaches at different flows. By introducing the weighted usable area (WUA) and hydraulic unit diversity index, combined with the suitability curves of the study species, the hydraulic characteristics and habitat suitability changes of two river reaches under different flows are summarized and analyzed, and the hydrogeomorphological process of the studied river section is generalized. Results: With the change in discharge, a positive correlation is observed between the maximum velocity and depth of the meandering river and the discharge, whereas the WUA and hydraulic unit index of the meandering river have relatively small changes. Under low discharge, the distribution of pool-riffle sequences can be seen in the meandering reach, which is essential to improve the ecological suitability and stability of the river. Conclusions: This study provides scientific sustentation for river restoration and fish conservation.
\end{abstract}

Keywords: Meandering; River morphology; Weighted usable area; Hydraulic units; Ecological suitability

\section{Introduction}

Rivers are a product of the Earth's evolutionary process and play an important role in the evolution of the Earth. With the evolution of nature, the flow and direction of rivers have also evolved, and the effects of natural bending and curving have been alternating, although the rivers tend to have slightly curved or bent forms $[1,2]$. The channel plan form is a direct representation of the spatial heterogeneity of the river geomorphology [3], which can be classified according to its plan form. The most widely used river classification method, proposed by Leopold, classified rivers into straight, meandering, and braided rivers [4]. Rust supplemented the river types into four categories: straight, meandering, braided, and reticulated rivers based on the meander ability and intertwining parameters [5]. Dong divided the plane morphology of rivers into three types: sinuosity/meandering, straight-low sinuosity, and multi-channels, which can be divided into braided, anastomosing/anabranching, and wandering [2]. Monotonous, low-meander reaches in the same area exhibit low habitat suitability for unstable flow conditions, while complexmeander, braided morphological reaches provide high spatial heterogeneity and are more suitable for habitats with unstable flow conditions [6]. However, at the same time, we need to note that we do not want to rectify all rivers into meandering rivers, for the actual problem we adhere to the principle of respect for nature, for some rivers subject to human interference, aim to restore through natural restoration-oriented, artificially guided ideas.

In the context of future impacts of climate change, river morphology is a decisive parameter for habitat conservation and restoration, and a driver of habitat quality [7]. The geomorphological complexity of rivers is the natural basis for biodiversity. It influences the dynamics of riverine ecosystems, both directly and indirectly, by interacting with the physical, chemical, and hydrological processes of a river [8]. The stability of a river structure is a key factor that influences the diversity of aquatic organisms, particularly benthic fauna [9]. Parsapour et al. [10] showed that variation in river morphology significantly influences habitat suitability, and that meandering rivers are more suitable for fish survival. Meandering rivers have extremely complex geomorphological features and constitute the natural basis for biodiversity. They not only effectively improve the stability of the river channel at both the overall and local river scales but also provide diverse habitats for differ- 
ent species, which is important for stabilizing the physical structure of the river and maintaining the ecosystem [11]. To quantitatively reveal the ecological significance of meandering rivers and their stabilities, the Chishui River, a mountainous river in southwest China, is selected as the study area for this research. As a first-order tributary of the Yangtze River, the Chishui River is a relatively natural mountainous river with low artificial influences, rich flora and fauna resources, and good water quality. Combined with field research, two typical river sections are selected and simulated using a hydrodynamic model. The local endemic fish, Procypris rabaudi (Tchang), is selected as the target species, and the ecological nature of the meandering river is analyzed based on its weighted usable area (WUA) changes. The stability of meandering rivers is quantified based on the distribution of hydraulic units (HUs) and their diversity. Diverse hydrodynamic conditions are the basis for fish survival. The novelty of this study is as follows: it introduces the concept of an HU and its diversity index and quantitatively analyzes the relationship between river planforms and hydrodynamic units, progressively, to clarify the correlation between geomorphic features and ecology.

\section{Methods}

\subsection{Study area}

The Chishui River (Fig. 1) is the largest first-order tributary on the right bank of the upper reaches of the Yangtze River. It is located in the border zone between the Yunnan-Guizhou Plateau and the Sichuan Basin in China, with high terrain to the east, south, and west, and low terrain to the north, most of which is mountainous, with local hills and alluvial basins. The mainstream of the Chishui River is $436.5 \mathrm{~km}$ long, with a total drop of $1475 \mathrm{~m}$, and its average gradient is $3.4 \%$. Owing to the interaction of the hydrological and geomorphological conditions, the mainstream of the Chishui River forms a diverse habitat from the upper to the lower reaches. One hundred and thirty-six species of fish are found in the basin, 42 of which are endemic to the upper reaches of the Yangtze River.

Based on actual field research in recent years, the following two sections are selected from the lower Chishui River. The first is the meandering reach (reach 1) with a length of $5.625 \mathrm{~km}$ and sinuosity of 1.98 . The straightlow sinuosity reach (reach 2 ) below the meandering reach is studied as a reference and for comparison. Its length and sinuosity are $1.583 \mathrm{~km}$ and $1.05 \mathrm{~km}$, respectively. The specific locations are shown in Fig. 1.

\subsection{Hydraulic models}

\subsubsection{Model description}

This study uses River2D, a depth-averaged twodimensional finite element simulation program developed by the Alberta University, Canada, which can be used for hydrodynamic and fish habitat simulations [12]. The River2D model is distinguished by using the approximate supercritical method and the wet and dry zone solution al- gorithm for the boundary part of the calculated river channel. Simultaneously, it provides a separate area division function that allows a more detailed grid to be divided for the calculation area separately, thus satisfying the individual solution of small areas within a large spatial scale, which is conducive to the accurate solution of hydrodynamics and habitats [13]. The hydrodynamic component of the River2D model is based on the two-dimensional, depthaveraged St. Venant equations expressed in a conservative form. These three equations represent the conservation of water mass and the two components of the momentum vector.

Conservation of mass:

$$
\frac{\partial H}{\partial t}+\frac{\partial q_{x}}{\partial x}+\frac{\partial q_{y}}{\partial y}=0
$$

Conservation of $\mathrm{x}$-direction momentum:

$$
\begin{aligned}
\frac{\partial q_{x}}{\partial t} & +\frac{\partial}{\partial x}\left(U q_{x}\right)+\frac{\partial}{\partial y}\left(V q_{x}\right)+\frac{g}{2} \frac{\partial}{\partial x} H^{2} \\
& =g H\left(S_{0 x}-S_{f x}\right)+\frac{1}{\rho}\left(\frac{\partial}{\partial x}\left(H \tau_{x x}\right)\right)+\frac{1}{\rho}\left(\frac{\partial}{\partial y}\left(H \tau_{x y}\right)\right)
\end{aligned}
$$

Conservation of y-direction momentum:

$$
\begin{aligned}
\frac{\partial q_{y}}{\partial t} & +\frac{\partial}{\partial x}\left(U q_{y}\right)+\frac{\partial}{\partial y}\left(V q_{y}\right)+\frac{g}{2} \frac{\partial}{\partial y} H^{2} \\
& =g H\left(S_{0 y}-S_{f y}\right)+\frac{1}{\rho}\left(\frac{\partial}{\partial x}\left(H \tau_{y x}\right)\right)+\frac{1}{\rho}\left(\frac{\partial}{\partial y}\left(H \tau_{y y}\right)\right)
\end{aligned}
$$

where $H$ is the depth of flow. $q_{x}$, and $q_{y}$ are the respective discharge intensities, which are related to the velocity components through

$$
\begin{aligned}
& q_{x}=H U \\
& q_{y}=H V
\end{aligned}
$$

$U$ and $V$ are the depth-averaged velocities in the $\mathrm{x}$ and y coordinate directions, respectively.

$g$ is the acceleration due to gravity; $\rho$ is the density of water; $S_{0 x}$ and $S_{0 y}$ are the bed slopes in the $x$ and $y$ directions, respectively $-S_{f x}$ and $S_{f y}$ are the corresponding friction slopes;

$\tau_{x x}, \tau_{x y}, \tau_{y x}, \tau_{y y}$ are the components of the horizontal turbulent stress tensor.

Based on years of hydrological data and topographic data combined with real-time kinematic (RTK) field measurements, the model roughness is taken as the average of the surveyed area, which is 0.04 . For the simulated flow values of 102.8, 306.9, 395.9, 540.4, 697.1, 1925, 3260, and $5020 \mathrm{~m}^{3} / \mathrm{s}$, the changes in water flow velocity and depth, WUA of target fish, distribution of the HUs, and diversity were studied. 


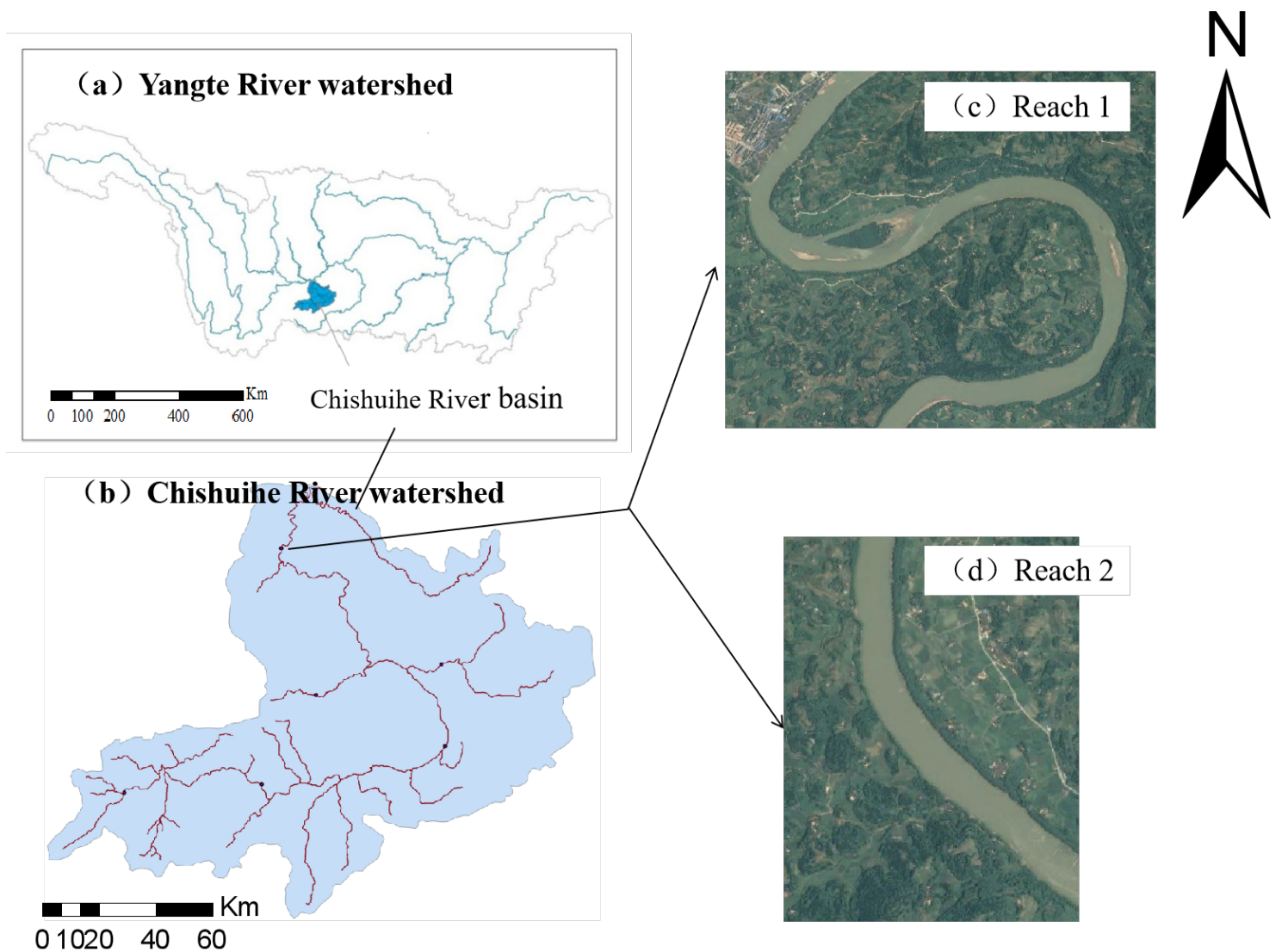

Fig. 1. Location of the Chishui river basin. (a) Yangte River watershed boundary. (b) Chishuihe River watershed boundary. (c) Study river reach 1. (d) Study river reach 2.

\subsubsection{Model validation}

The downstream water level boundary is determined based on the hydrological data, and the water level boundary under $102.8 \mathrm{~m}^{3} / \mathrm{s}$ flow is $212.5 \mathrm{~m}$. The accuracy of the model is evaluated by comparing the measured $(\mathrm{Q}=118$ $\mathrm{m}^{3} / \mathrm{s}$ ) and simulated values of the velocities of each crosssession, as shown in Fig. 2 and Table 1. The measured flow rates are obtained by renting a local yacht and averaging several measurements with an LS1260B flow meter (Fig. 3).

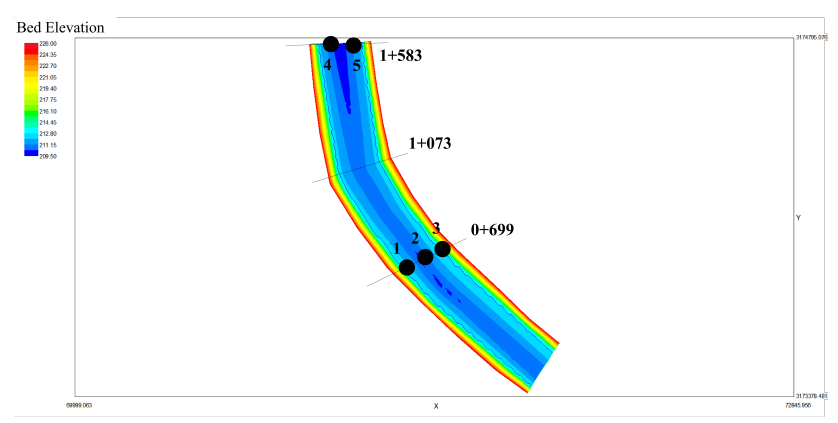

Fig. 2. Model rate determination point distribution.
Table 1. Comparison of the measured and simulated values of the velocities.

\begin{tabular}{cccc}
\hline No. & $\begin{array}{c}\text { Measured } \\
\text { velocity }(\mathrm{m} / \mathrm{s})\end{array}$ & $\begin{array}{c}\text { Simulated } \\
\text { velocity }(\mathrm{m} / \mathrm{s})\end{array}$ & Error (\%) \\
\hline 1 & 0.64 & 0.643 & $0.47 \%$ \\
2 & 0.65 & 0.667 & $2.62 \%$ \\
3 & 0.28 & 0.286 & $2.14 \%$ \\
4 & 0.44 & 0.445 & $1.14 \%$ \\
5 & 0.5 & 0.489 & $-2.20 \%$ \\
\hline
\end{tabular}

\subsection{WUA and habitat suitability curves}

The fish habitat component of the River2D is based on the WUA [14] concept used in the physical habitat simulation model (PHABSIM) family of fish habitat models. The WUA calculation is based on three assumptions: (1) There is a certain correlation between habitat suitability and flow discharge; (2) Changes in the river's micro-environmental factors, such as water depth and velocity, are the main factors that affect the distribution and quantity of species; (3) Riverbed topography remains constant during the simulation.

The calculation of WUA is shown as follows:

$$
C S F_{i}=V_{i} \times D_{i} \times C_{i}
$$




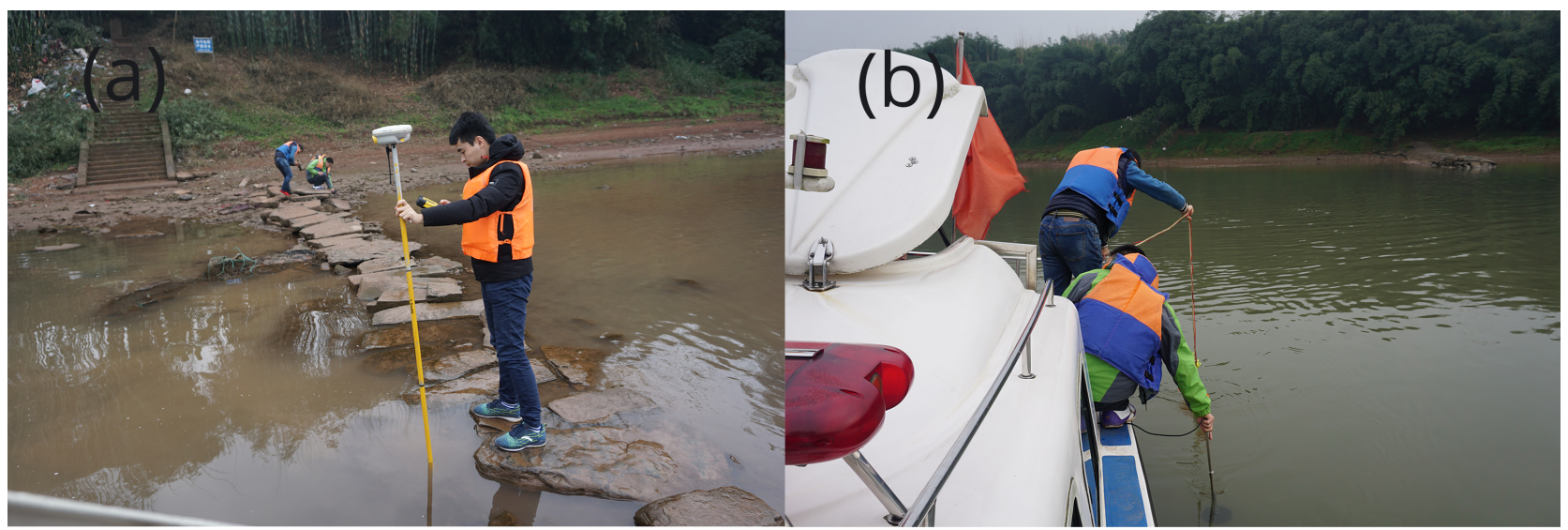

Fig. 3. Field research. (a) Topographic survey. (b) Measuring velocity.

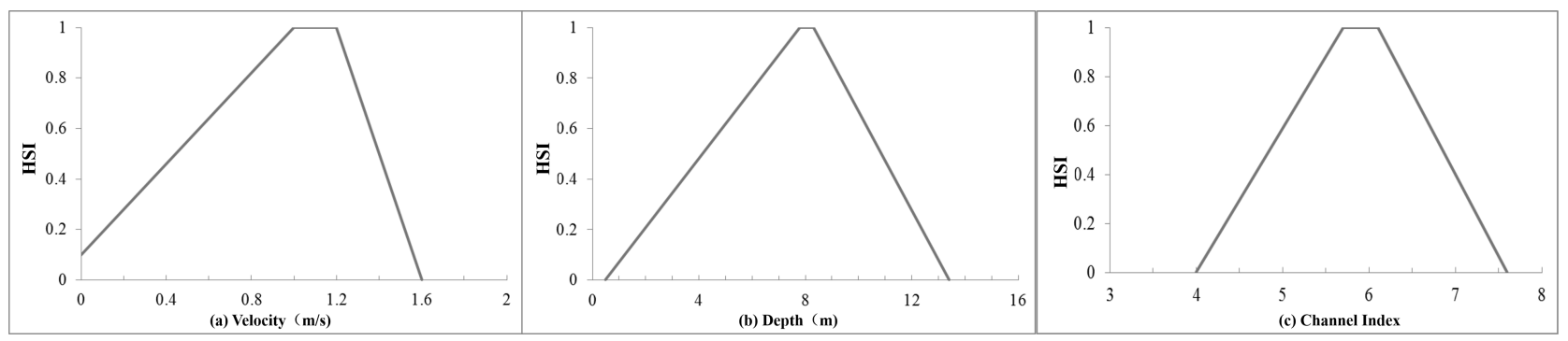

Fig. 4. Habitat suitability curves for adult Procypris rabaudi (Tchang). (a) Velocity suitability curve. (b) Depth suitability curve. (c) Channel Index.

$$
W U A=\sum_{i=1}^{n} C S F\left(V_{i}, C_{i}, D_{i}\right) \times A_{i}
$$

CSF $\left(V_{i}, D_{i}, C_{i}\right)$ : composite suitability index at every point; $i$ : number of points; $V_{i}$ : velocity suitability in$\operatorname{dex} ; D_{i}$ : depth suitability index; $C_{i}$ : suitability index of the channel index; $A_{i}$ : tributary area associated with the point.

A key factor that determines the accuracy of habitat simulation results is the habitat suitability index (HSI), which is used to quantitatively describe the suitability of species to habitat, with values ranging from 0 to $1-0$ being completely unsuitable and 1 being completely suitable; the larger the value, the better the suitability [15]. By combining field research with the distribution of fish resources, the endemic and rare fish of the Chishui River, Procypris rabaudi (Tchang), is selected as the target fish. The HSIs characterize the adaptability to factors such as flow velocity, depth, and channel index throughout the study area. Based on previous literature analysis $[16,17]$, a review of local county records, inquiries with relevant local fishery departments, and field surveys to measure the hydrodynamic conditions of the areas where the fish commonly exist, the suitability curve of the velocity, depth, and channel index is established, as shown in Fig. 4.

\subsection{Diversity of hydraulic units}

The HUs generally consist of basic habitats for aquatic organisms, representing uniform patches of water flow and substrate characteristics [18,19]. Based on the field research data and considering the actual conditions of hydrodynamics and substrate in the study section, the hydraulic units of the study section are generalized into pool, riffle, glide, and slack water (Table 2) by combining the research of related scholars [20].

The richer the diversity of the HUs, the more diverse their hydraulic conditions are, and the more suitable their habitats are for biological survival. Their diversity is expressed by the Shannon $(\mathrm{H})$ diversity index. The higher its value, the better the degree of depth and velocity flow heterogeneity and the more stable the survival of organisms in the region [21].

$$
H=-\sum_{i=1}^{m}\left(P_{i}\right) \times \log _{2}\left(P_{i}\right)
$$

In Eqn. $8, H$ denotes the diversity index, $\mathrm{m}$ denotes the number of different types of areas, and $P_{i}$ denotes the proportion of the study area occupied by the ith type. 

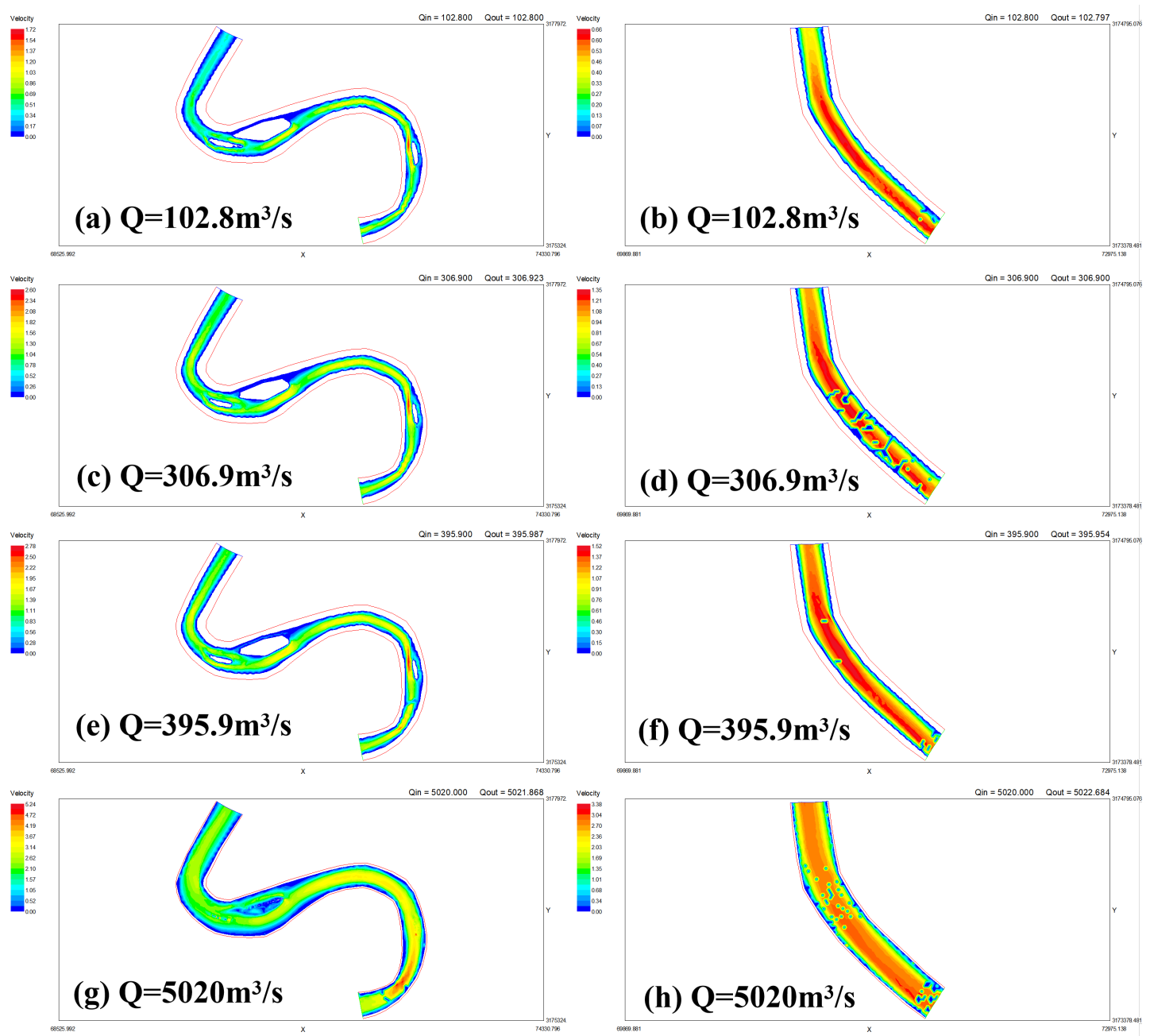

Fig. 5. Simulated velocity in reaches 1 and 2. (a) Velocity of reach 1 with flow of $102.8 \mathrm{~m}^{3} / \mathrm{s}$. (b) Velocity of reach 2 with flow of $102.8 \mathrm{~m}^{3} / \mathrm{s}$. (c) Velocity of reach 1 with flow of $306.9 \mathrm{~m}^{3} / \mathrm{s}$. (d) Velocity of reach 2 with flow of $306.9 \mathrm{~m}^{3} / \mathrm{s}$. (e) Velocity of reach 1 with flow of $395.9 \mathrm{~m}^{3} / \mathrm{s}$. (f) Velocity of reach 2 with flow of $395.9 \mathrm{~m}^{3} / \mathrm{s}$. (g) Velocity of reach 1 with flow of $5020 \mathrm{~m}^{3} / \mathrm{s}$. (h) Velocity of reach 2 with flow of $5020 \mathrm{~m}^{3} / \mathrm{s}$.

Table 2. Hydraulic unit classification.

\begin{tabular}{ll}
\hline HUS & \multicolumn{1}{c}{ Conditions } \\
\hline Pool & depth $>1 \mathrm{~m}$ and velocity $<0.5 \mathrm{~m} / \mathrm{s}$ \\
Riffle & depth $<1 \mathrm{~m}$ and velocity $>0.5 \mathrm{~m} / \mathrm{s}$ \\
Glide & depth $>1 \mathrm{~m}$ and velocity $>0.5 \mathrm{~m} / \mathrm{s}$ \\
Slack water & depth $<1 \mathrm{~m}$ and velocity $<0.5 \mathrm{~m} / \mathrm{s}$ \\
\hline
\end{tabular}

\section{Results}

\subsection{Change in hydrodynamic conditions}

Among the 12 different discharge rates of the two river sections, the velocity and depth of 24 cases are simulated, and six typical cases are selected, as shown in Figs. 5,6 and Table 3 .

The maximum velocity and water depth of the two reaches increase gradually with discharge (Fig. 7). The maximum velocity is logarithmically related to the discharge. For the maximum velocity of reach 1 , the corre-
Table 3. Maximum velocity and depth at each flow condition.

\begin{tabular}{lcccc}
\hline \multirow{2}{*}{$\mathrm{Q}\left(\mathrm{m}^{3} / \mathrm{s}\right)$} & \multicolumn{2}{c}{ Maximum velocity } & \multicolumn{2}{c}{ Maximum depth } \\
\cline { 2 - 5 } & Reach 2 & Reach 1 & Reach 2 & Reach 1 \\
\hline 102.8 & 0.66 & 1.51 & 3.19 & 9.53 \\
136.8 & 0.81 & 1.72 & 3.26 & 9.7 \\
176.4 & 0.97 & 1.95 & 3.35 & 9.88 \\
230.7 & 1.15 & 2.22 & 3.46 & 10.13 \\
306.9 & 1.35 & 2.52 & 3.63 & 10.44 \\
395.9 & 1.52 & 2.78 & 3.82 & 10.76 \\
406.2 & 1.54 & 2.81 & 3.84 & 10.8 \\
540.4 & 1.75 & 3.17 & 4.13 & 11.21 \\
697.1 & 1.94 & 3.4 & 4.46 & 11.63 \\
1925 & 2.76 & 3.89 & 6.94 & 14.04 \\
3260 & 3.02 & 4.66 & 9.39 & 15.83 \\
5020 & 3.16 & 5.65 & 12.24 & 17.08 \\
\hline
\end{tabular}



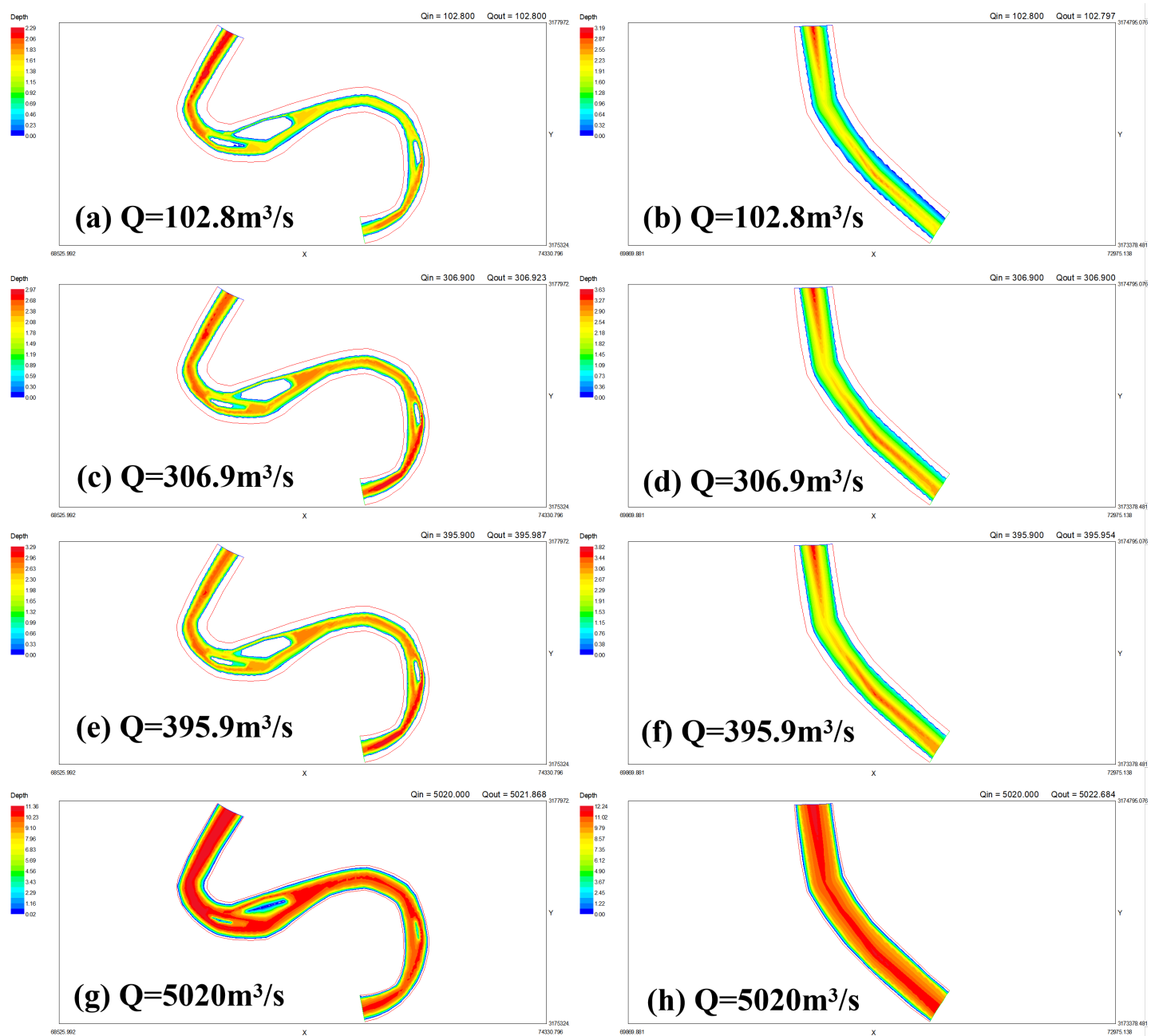

Fig. 6. Simulated depth in reaches 1 and 2. (a) Depth of reach 1 with flow of $102.8 \mathrm{~m}^{3} / \mathrm{s}$. (b) Depth of reach 2 with flow of 102.8 $\mathrm{m}^{3} / \mathrm{s}$. (c) Depth of reach 1 with flow of $306.9 \mathrm{~m}^{3} / \mathrm{s}$. (d) Depth of reach 2 with flow of $306.9 \mathrm{~m}^{3} / \mathrm{s}$. (e) Depth of reach 1 with flow of $395.9 \mathrm{~m}^{3} / \mathrm{s}$. (f) Depth of reach 2 with flow of $395.9 \mathrm{~m}^{3} / \mathrm{s}$. (g) Depth of reach 1 with flow of $5020 \mathrm{~m}^{3} / \mathrm{s}$. (h) Depth of reach 2 with flow of $5020 \mathrm{~m}^{3} / \mathrm{s}$.

lation is

$$
y=0.9787 \ln x-3.0848\left(R^{2}=0.9766\right)
$$

For the maximum velocity of reach 2 , the correlation is

$$
y=0.6827 \ln x-2.5413\left(R^{2}=0.9952\right)
$$

For the maximum depth of reach 1 , the correlation is

$$
y=1.9682 \ln x-0.5309\left(R^{2}=0.9461\right)
$$

For the maximum depth of reach 2 , the correlation is

$$
y=0.0019 x+3.0855\left(R^{2}=0.9979\right)
$$

The maximum velocity and depth of the meandering section (reach 1) are higher than those of the straight-low sinuosity section (reach 2) in the same discharge. This indicates that the increase in sinuosity provides more abundant velocity and depth conditions, which create a more effective habitat for fish. In terms of landform patterns, the high spatial heterogeneity of the meandering section results in the diversity of the morphological units, such as pool, riffle, and island, providing an effective boundary for the diversity of hydraulic conditions. Furthermore, the variation rate of the maximum velocities of the meandering section is lower than that of the straight-low sinuosity section, which shows that the regulation ability of the hydrological regime in the meandering reach is better.

The improvement in the sinuosity helps control the velocity more effectively; thus, the natural meandering rivers have more diverse and stable hydraulic conditions. During flood season, with the large fluctuations in discharge, stable hydraulic situations can provide more effective refuge for aquatic organisms. 


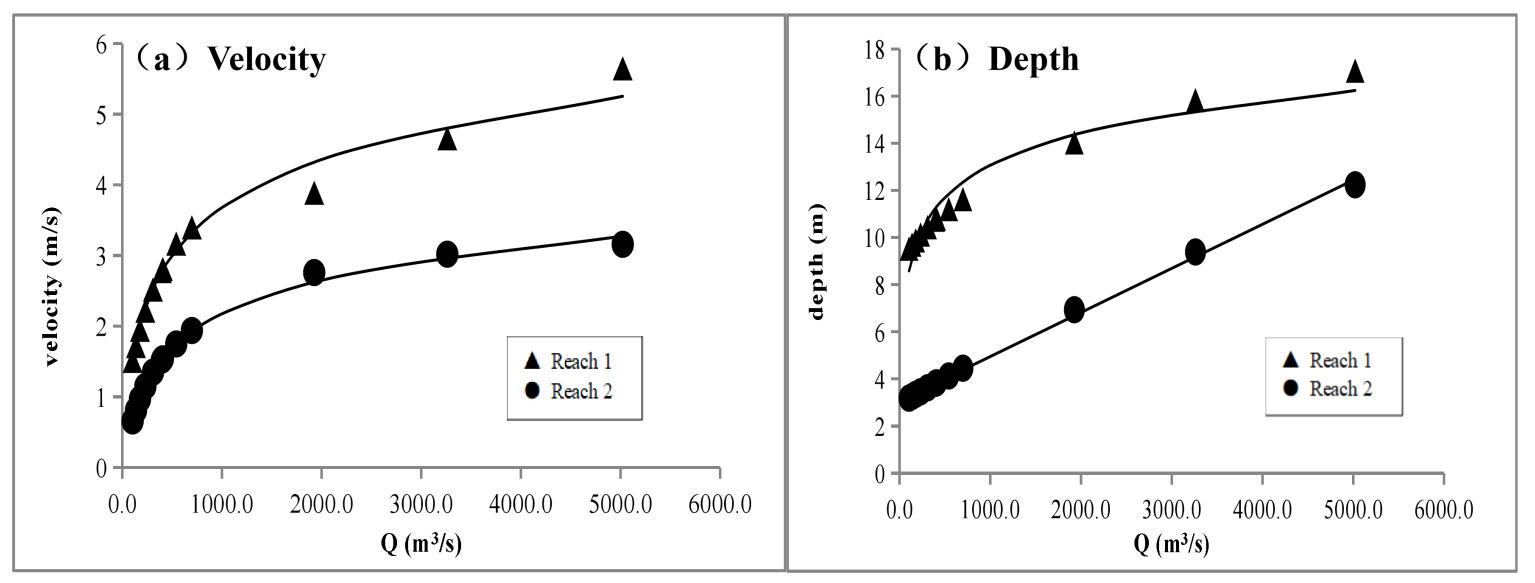

Fig. 7. Relationships between the maximum velocities and depths and discharge. (a) Velocity. (b) Depth.

Table 4. WUA of different discharges.

\begin{tabular}{lcccccc}
\hline \multirow{2}{*}{ Q $\left(\mathrm{m}^{3} / \mathrm{s}\right)$} & \multicolumn{2}{c}{ Reach 2} & \multicolumn{2}{c}{ Reach 1 } & \multicolumn{2}{c}{ WUA/TA } \\
\cline { 2 - 6 } & WUA $\left(\mathrm{m}^{2}\right)$ & TA $\left(\mathrm{m}^{2}\right)$ & WUA $\left(\mathrm{m}^{2}\right)$ & TA $\left(\mathrm{m}^{2}\right)$ & Reach 2 & Reach 1 \\
\hline 102.8 & 19444 & 395387 & 78862 & 1922447 & $4.92 \%$ & $4.10 \%$ \\
306.9 & 46160 & 395387 & 155148 & 1922447 & $11.67 \%$ & $8.07 \%$ \\
395.9 & 40730 & 395387 & 176293 & 1922447 & $10.30 \%$ & $9.17 \%$ \\
540.4 & 22310 & 395387 & 200017 & 1922447 & $5.64 \%$ & $10.40 \%$ \\
697.1 & 11671 & 395387 & 192418 & 1922447 & $2.95 \%$ & $10.01 \%$ \\
1925 & 4588 & 395387 & 143966 & 1922447 & $1.16 \%$ & $7.49 \%$ \\
3260 & 3655 & 395387 & 157023 & 1922447 & $0.92 \%$ & $8.17 \%$ \\
5020 & 266 & 395387 & 92500 & 1922447 & $0.07 \%$ & $4.81 \%$ \\
\hline
\end{tabular}

\subsection{River morphology and suitability}

The weighted usable-habitat area is a visual representation of the habitat suitability of the rock carp. The results of the River2D model at each flow condition are analyzed to extract the WUA, total habitat area (TA), and ratio of weighted usable area (WUA/TA) for the two reaches at each flow condition in Table 4.

The discharge-WUA correlation curves are established as shown in Fig. 8. The WUA of reach 2 increases and then decreases. The largest WUA with an area ratio of $11.67 \%$ is in the discharge of $306.9 \mathrm{~m}^{3} / \mathrm{s}$. Those with area ratios of $0.92 \%$ and $0.07 \%$ are in the discharge of 3260 $\mathrm{m}^{3} / \mathrm{s}$ and $5040 \mathrm{~m}^{3} / \mathrm{s}$, respectively. This shows that during the flood season there is less habitat in reach 2 for Procypris rabaudi (Tchang). The WUA of reach 1 shows a doublepeak form in the discharge of $540.4 \mathrm{~m}^{3} / \mathrm{s}$ in the wet season and $3260 \mathrm{~m}^{3} / \mathrm{s}$, with area ratios of $10.40 \%$ and $8.17 \%$, respectively. Subsequently, with the increase in discharge, the velocity increases and deviates from the optimal value, which reduces the habitat area.

\subsection{River morphology and hydraulic units}

Based on the simulation results of the hydrodynamic model, the changes in the hydraulic units in the two river sections under different flows are combed, and the rela-

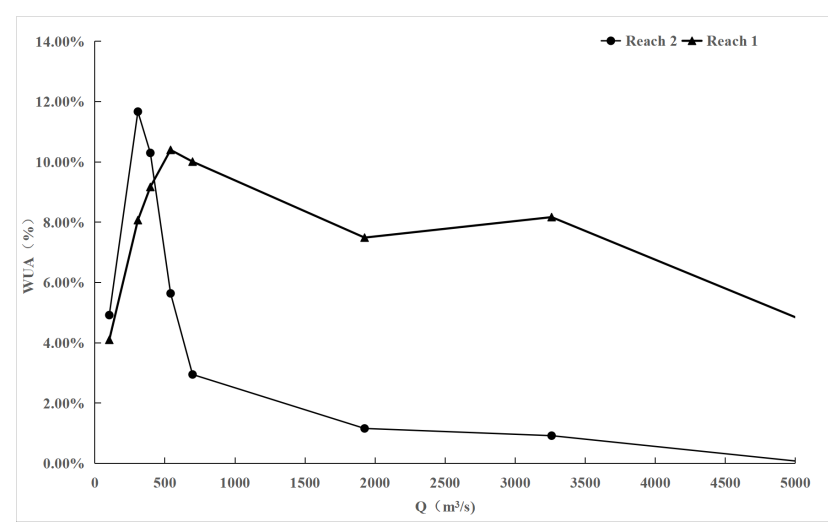

Fig. 8. Discharge-WUA correlation curves of reach 1 and reach 2 .

tionship between the meandering and hydraulic units is discussed and analyzed. The summarized results are shown in Tables 5,6, and the percentage refers to the proportion of each hydraulic unit to the total plan area of the river.

In both reach 1 and reach 2, with the increasing flow, the area of the pool shows a decreasing trend, that of the glide shows an increasing trend, that of the slack water shows a decreasing trend, and the waterless area shows a decreasing trend. For the riffle unit, reach 1 shows a de- 
Table 5. Variation in the proportion of the hydraulic units in reach 1 at different flows.

\begin{tabular}{lcccc}
\cline { 1 - 4 } $\mathrm{Q}\left(\mathrm{m}^{3} / \mathrm{s}\right)$ & \multirow{2}{*}{102.8} & 697.1 & 1925 & 5020 \\
\cline { 1 - 4 } HUS & & & & \\
Pool & $26.81 \%$ & $18.58 \%$ & $18.50 \%$ & $13.17 \%$ \\
Riffle & $0.71 \%$ & $0.06 \%$ & $0.06 \%$ & $0.33 \%$ \\
Glide & $10.70 \%$ & $38.71 \%$ & $49.25 \%$ & $62.27 \%$ \\
Slack water & $12.36 \%$ & $5.22 \%$ & $2.30 \%$ & $3.14 \%$ \\
Waterless area & $49.42 \%$ & $37.43 \%$ & $29.89 \%$ & $21.09 \%$ \\
\hline
\end{tabular}

Table 6. Variation in the proportion of the hydraulic units in reach 2 at different flows.

\begin{tabular}{lcccc}
\cline { 1 - 4 } $\mathrm{Q}\left(\mathrm{m}^{3} / \mathrm{s}\right)$ & \multirow{2}{*}{102.8} & 697.1 & 1925 & 5020 \\
\cline { 1 - 4 } HUS & & & & \\
\cline { 1 - 5 } Pool & $19.82 \%$ & $11.26 \%$ & $11.94 \%$ & $5.33 \%$ \\
Riffle & $0.00 \%$ & $0.00 \%$ & $0.00 \%$ & $0.67 \%$ \\
Glide & $23.12 \%$ & $59.02 \%$ & $64.53 \%$ & $81.99 \%$ \\
Slack water & $24.58 \%$ & $3.09 \%$ & $2.79 \%$ & $3.14 \%$ \\
Waterless area & $32.48 \%$ & $26.63 \%$ & $20.73 \%$ & $8.87 \%$ \\
\hline
\end{tabular}

creasing then increasing trend, and reach 2 shows an increasing trend. Secondly, in terms of the change interval, reach 1 is smaller than reach 2 , and the meandering river has a better ability to regulate the water flow than the smooth and straight river.

Fig. 9 shows that the water-skiing unit increases rapidly with the increasing flow, almost covering the entire river course. Moreover, it presents uniformity, and reach 1 is slightly better than reach 2 . At low discharge, the spatial distribution of the hydraulic units in reach 2 presents aggregation, whereas that in reach 1 presents alternation. In addition, a pool-riffle sequence occurs in the bend. Based on the above results, the hydraulic unit diversity of the two river sections at different flows is calculated, and the results are shown in Table 7.

Table 7. Variation in the proportion of the HUs in reach 2 at different flows.

\begin{tabular}{lcc}
\hline $\mathrm{Q}\left(\mathrm{m}^{3} / \mathrm{s}\right)$ & Reach 1 & Reach 2 \\
\hline 102.8 & 1.78 & 1.97 \\
697.1 & 1.74 & 1.46 \\
1925 & 1.61 & 1.38 \\
5020 & 1.46 & 0.93 \\
\hline
\end{tabular}

The diversity of the HUs in both reaches 1 and 2 gradually decreases with the increasing flow, and for the aquatic organisms in the studied river segments, small flows are more likely to maintain the stability of the river ecosystem. As shown in Fig. 9, the diversity of the HUs in straight rivers under low flows is greater than that in meandering rivers, which is somewhat different from our conventional conjecture. Therefore, under constant low flow conditions, meandering rivers and straight rivers need to be analyzed in conjunction with ecological protection objectives. At different flows, river segment 1 decreases from 1.78 to 1.46 a change of $18.0 \%$. River segment 2 decreases from 1.97 to 0.93 - a change of $52.8 \%$. Based on the above analysis, meandering rivers do not change rapidly with the flow and are more stable in response to hydrological changes than straight rivers [22].

\section{Discussion}

River sinuosity is an expression of the self-organizing behavior of river systems, an ongoing natural process by which rivers in different parts of the world shape their unique forms [23]. Meandering rivers contain a variety of spatially heterogeneous geomorphic units, which are important for stabilizing the physical structure of rivers and maintaining ecosystems - these are gradually becoming a research hotspot in river ecological geomorphology [22]. Complex geomorphological features change water flow and sediment conditions, creating diverse microhabitats. As the natural river morphology changes, the river water environment changes in response, with changes in the diversity and abundance of river organisms and a certain responsive relationship [20,24-26].

Hauer et al. [27] took the Grosse Mühl River in northern Austria as the study area and used the hydrodynamic model to simulate and compare the changes in habitat characteristics of meandering rivers and plane bed reaches under different flows. The results showed that a meandering river has a stronger regulation ability and can ensure certain suitability even under low flows. This is consistent with the results of our study. Combined with Table 3, the proportion of WUA/TA in reach 1 under different flows ranges from $4.1 \%$ to $10.4 \%$, with a variation range of $6.3 \%$. Under different flows, the proportion of WUA/TA in reach 2 ranges from $0.07 \%$ to $11.67 \%$, with a variation range of $11 \%$. Meandering rivers are notably more stable. In addition, the results from Hauer et al. [27] show that fish habitats are sensitive to flow changes. This conclusion is consistent with Table 4.

Wang et al. [28] pointed out that meandering rivers contain a variety of spatially heterogeneous, the main channel of which is mainly a pool-riffle sequence. A pool is often located at the apex of the meandering river bends and on the outer side (or concave bank side) of the convex part of the deep channel bend. A riffle is a shallow channel between two bays, located between two adjacent crests of the deep channel, and its starting point is often at the end of the bend of a meandering river [28]. Combined with Fig. 9, the sequence of pool and riffle in river section 1 is consistent with the above summary. Moreover, river section 2 does not have shallow units at low flows, and the river morphology influences the type and composition of the HUs.

Considering the habitat from the perspective of the 

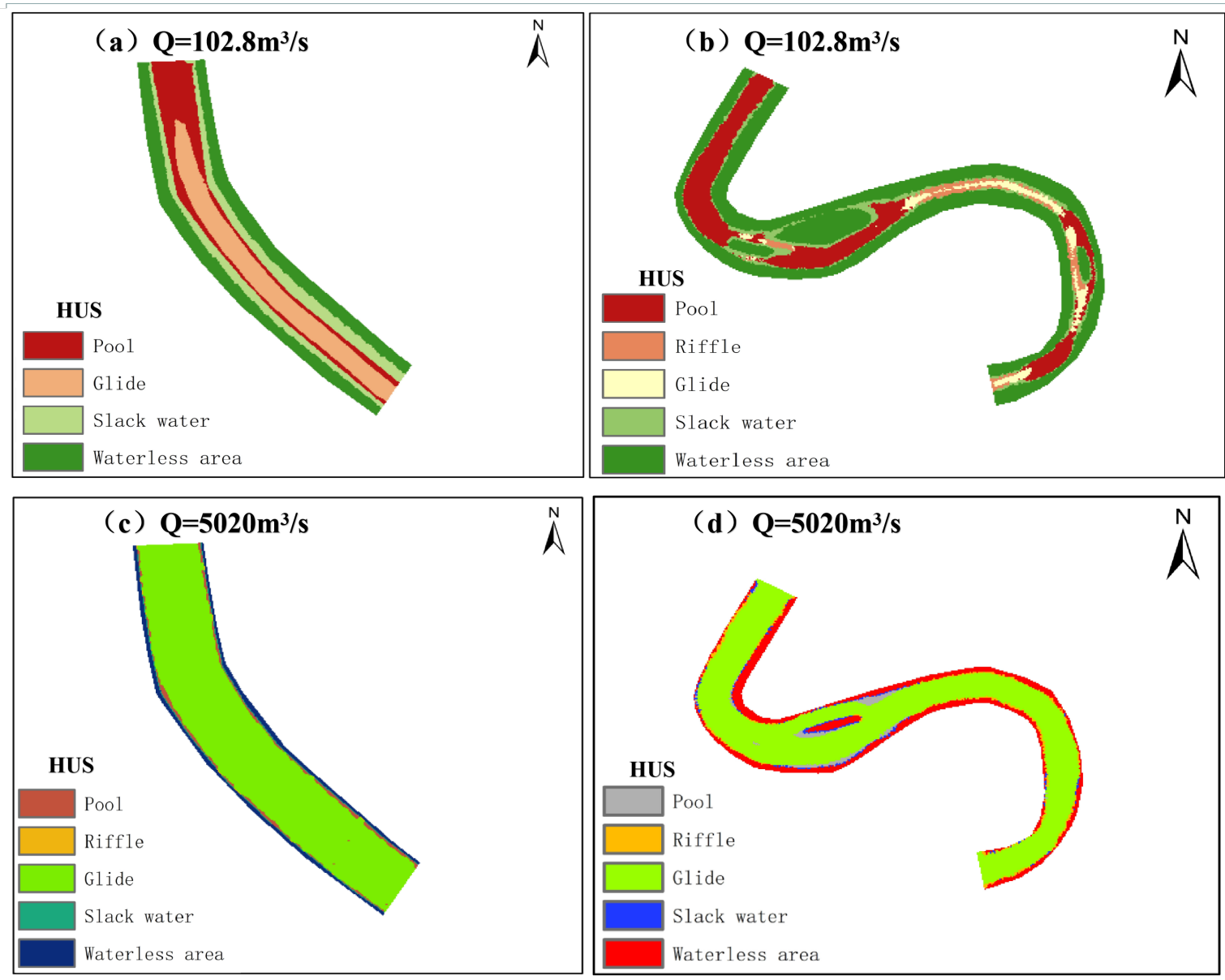

Fig. 9. Discharge-WUA correlation curves of reach 1 and reach 2. (a) $Q=102.8 \mathrm{~m}^{3} / \mathrm{s}$, reach 2. (b) $\mathrm{Q}=102.8 \mathrm{~m}^{3} / \mathrm{s}$, reach 1 . (c) $\mathrm{Q}=$ $5020 \mathrm{~m}^{3} / \mathrm{s}$, reach 2. (d) $\mathrm{Q}=5020 \mathrm{~m}^{3} / \mathrm{s}$, reach 2 .

reach 1

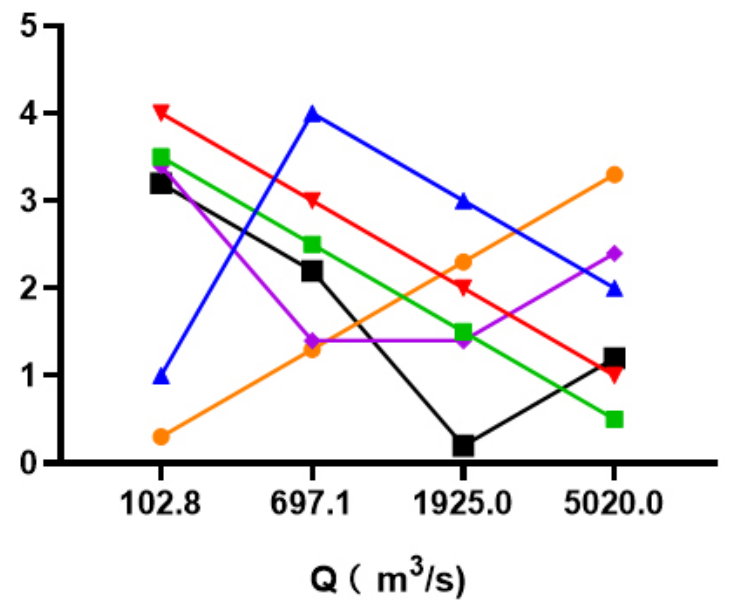

$\rightarrow$ WUA $\rightarrow$ Diversity of hydraulic units Index

$\rightarrow$ pool area $\rightarrow$ riffle area

$\rightarrow$ glide area $\rightarrow$ slack water area reach 2

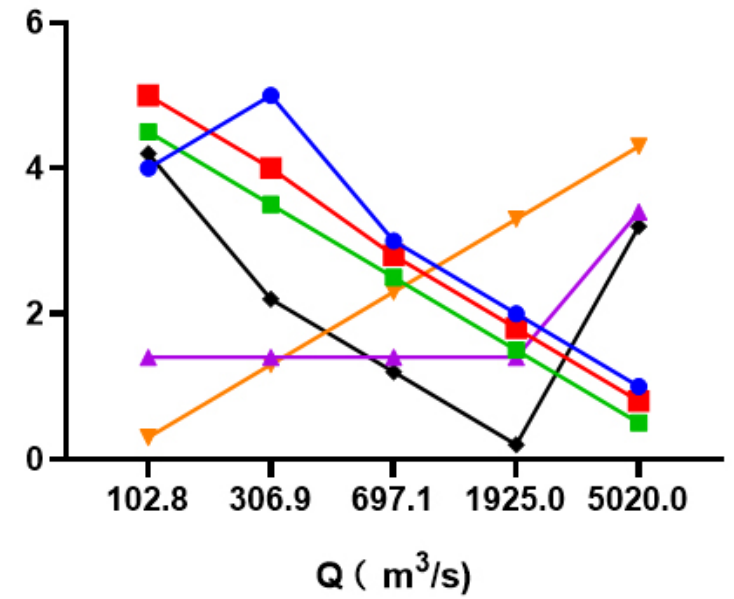

WUA - Diversity of hydraulic units Index

- pool area $\leftarrow$ riffle area

$\rightarrow$ glide area $\rightarrow$ slack water area

Fig. 10. Trend analysis of changes based on WUA. 
$\mathrm{HU}$, the spatial location suitable for survival can be located more accurately. Chung [29] used the River2D model to simulate the hydraulics of ten geomorphological types of the Gapcheon River (rapid riffle, bypass channel, main channel connected pool, curved section pool, unconnected pool, abandoned channel, pool with bottom liner, pool below dam, and rocky pool) and bathymetry as well as flow suitability curves to analyze the weighted available habitat area for zacco platypus minnow using water depth and velocity suitability curves. This indicates that the main channel connection to deep pools is extremely important for fish survival. From the above, the type of the $\mathrm{HU}_{S}$, connectivity between them affects the survival of fish habitat. Combined with Tables 4,5,6, we analyze the diversity index of the $\mathrm{HU}$ and the trend of each $\mathrm{HU}$ based on the change of the WUA, which is shown in Fig. 10. The vertical coordinates of Fig. 10 do not indicate the size, but the size ranking under the corresponding flow rate. Combined with Table 4, because the WUA in the flow rate of 102.8 and $697.1 \mathrm{~m}^{3} / \mathrm{s}$ between the inflection point, so calculate the inflection point $306.9 \mathrm{~m}^{3} / \mathrm{s}$ under the corresponding hydraulic unit diversity index, the area of each hydraulic unit. Fig. 10 shows that for the target fish, Procypris rabaudi (Tchang), there is no trend of the same curve of habitat suitability with the change of flow in either river sections 1 or 2. When studying the habitat suitability of fish from the perspective of HUs, not only are the type and diversity considered but also the connectivity between the units.

Macura et al. [30] studied the effects of mountain stream morphology and hydraulic characteristics on fish habitat to derive optimal depths of microhabitats for stream restoration measures and assessment of water withdrawal impacts. Based on the study of the relationship between river morphology and fish habitat, Mouton et al. [31] proposed an integrated modeling approach to simulate and assess the ecological impacts of changes in the physical habitat of rivers. Based on previous studies, this study analyzes the stability and ecology of meandering rivers, introduces the definition of sinuosity, and explores the relationship between sinuosity and fish habitat. Combined with the concept of geomorphic units, this paper can provide an intuitive basis for the restoration of related damaged rivers. Based on relevant environmental biomonitoring techniques [32-34], combined with the relevant analytical methods presented in this paper, it is possible to determine easy steps for the design of river restoration, especially the restoration of channelized rivers. In addition, the spatial distribution of aquatic vegetation can be considered to promote the natural restoration of the river. Vegetation can exert significant control river morphology by five basic mechanisms: resistance to flow, streambank robustness, sediment layers, formation of vegetated debris dams, and river sedimentation [35]. Parker et al. [36] proposed that riparian vegetation can increase the riparian roughness and inhibit the horizontal narrowing of the river bay.

\section{Conclusions}

In this study, the River2D model is applied to analyze the hydraulic characteristics and habitat suitability of adult fish in two reaches of the lower Chishui River. First, regarding the relationship between hydraulic characteristics and sinuosity, the data in this study confirms that a meandering river reach has richer velocity and depth conditions, and the regulation ability under high flow is significantly better than that of a straight river reach. From 102.8 to $5020 \mathrm{~m}^{3} / \mathrm{s}$, the variations in the maximum velocity and depth in river reach 1 are $73.3 \%$ and $44.2 \%$, respectively, which are smaller than the corresponding values in river reach $2-79.1 \%$ and $73.9 \%$. Secondly, regarding the relationship between habitat suitability and sinuosity, the data confirms that both the values of the WUA under low and high flows and the overall variation trend are significantly better in reach 1 than reach 2. Moreover, the greater the sinuosity, the higher the habitat suitability. Finally, regarding the relationship between the HUs and sinuosity, this study introduces the concept of hydraulic unit diversity and determines that the HUs decrease with increasing discharge, with the minimum values of 1.46 and 0.93 for reach 1 and reach 2, respectively. Moreover, the overall HUs of reach 1 are better than those of reach 2 . Under certain conditions, the higher the sinuosity, the greater the HU diversity, and a certain sensitivity arises between the HUs and discharge. Most rivers in nature are meandering, and the overall stability of meandering rivers is higher. Under the premise of the harmonious coexistence between humans and nature, it is reasonable to preserve nature and reduce human interference. Based on previous work, this study quantifies and clarifies the positive effects of meandering rivers by taking natural meandering rivers as the research object, which can provide a theoretical basis for local river ecological management.

Several issues could be addressed from this study, such as the ecological aspects of meanders, which could be improved by adding long series of aquatic monitoring data, provided there is sufficient time and financial resources, to achieve a more scientific approach. In terms of the distribution of HUs, a more detailed division can be made according to the actual situation of the studied river section, and more suitable HUs can be added, such that the regulation of meandering rivers in response to flow changes can be adequately studied. However, these can still be further improved in subsequent studies.

\section{Author contributions}

ZCY - Investigation, Data curation, Writing - original draft; JZ - Methodology, Data curation, Writing - original draft; HTW-Investigation, Data curation, Writing - original draft. JYZ - Writing - review \& editing, Funding acquisition. ZRD - Writing - review \& editing. WQP-Project administration, Conceptualization, Methodology. XFZInvestigation, Methodology. 


\section{Ethics approval and consent to participate}

Not applicable.

\section{Acknowledgment}

Thanks to all the peer reviewers for their opinions and suggestions.

\section{Funding}

This study was funded by the National Natural Science Foundation of China for Youth (No. 51509271), Special Funds for Public Industry Research Projects of the National Ministry of Water Resources (No. 201501030), and Special Funds for Research Projects of the China Institute of Water Resources and Hydropower Research (No. WE0145B532017).

\section{Conflict of interest}

The authors declare no conflict of interest.

\section{References}

[1] Hooke JM. Complexity, self-organisation and variation in behavior in meandering rivers. Geomorphology. 2007; 91: 236258.

[2] Dong Z. River restoration. China Water \& Power Press: Beijing. 2013.

[3] Venarsky MP, Walters DM, Hall RO, Livers B, Wohl E. Shifting stream planform state decreases stream productivity yet increases riparian animal production. Oecologia. 2018; 187: 167180.

[4] Leopold LB, Wolman MG, Miller JP, Wohl E. Fluvial Processes in Geomorphology. Courier Dover: Mineola, New York. 2020.

[5] Rust BR. A classification of alluvial channel systems. Fluvial Sedimentology. 1977; 5: 187-198.

[6] Person E, Bieri M, Peter A, Schleiss AJ. Mitigation measures for fish habitat improvement in Alpine rivers affected by hydropower operations. Ecohydrology. 2014; 7: 580-599.

[7] Hauer C, Unfer G, Holzmann H, Schmutz S, Habersack H. The impact of discharge change on physical instream habitats and its response to river morphology. Climatic Change. 2013; 116: 827-850.

[8] Elosegi A, Díez J, Mutz M. Effects of hydromorphological integrity on biodiversity and functioning of river ecosystems. Hydrobiologia. 2010; 657: 199-215.

[9] Cupşa D, Birkas M, Telcean I. Studies upon the structure and dynamics of the benthic macroinvertebrate communities from two habitats of The Ier River's Channel (Bihor county, Romania). Biharean Biologist. 2009; 3: 59-70.

[10] Parsapour-Moghaddam P, Brennan CP, Rennie CD, Elvidge CK, Cooke SJ. Impacts of Channel Morphodynamics on Fish Habitat Utilization. Environmental Management. 2019; 64: 272-286.

[11] Nagayama S, Nakamura F. The significance of meandering channel to habitat diversity and fish assemblage: a case study in the Shibetsu River, northern Japan. Limnology. 2018; 19: $7-$ 20.

[12] Steffler P, Blackburn J. Two-dimensional depth-averaged model of river hydrodynamics and fish habitat. [J]. River2D User's Manual, University of Alberta: Canada. 2002.

[13] Roh K, Park S, Jin Y, Park M. Study on ecological instream flow estimation using River2D model in the Seomjin River. Journal of Korean Society on Water Environment. 2011; 27: 822-829.
[14] Bovee KD. A guide to stream habitat analysis using the instream flow incremental methodology (Vol. 1). Western Energy and Land Use Team, Office of Biological Services, Fish and Wildlife Service, US Department of the Interior: 2625 Redwing Road, Fort Collins, Colorado, 1982.

[15] Yi Y, Wang Z, Yang Z. Two-dimensional habitat modeling of Chinese sturgeon spawning sites. Ecological Modelling. 2010; 221: 864-875.

[16] Le P, Chen Y. Red book of endemic animals in China (Fish). Science and Technology Press: Beijing. 1998.

[17] Liu F. Fish community ecology in Chishui River. Doctoral dissertation, Dissertation. University of Chinese Academy of Sciences: Beijing. 2013.

[18] Phillips JD. Hydraulic units of the lower Sabine River. Copperhead Road Geosciences: 720 Bullock Place, Lexington, KY, 2011.

[19] Brierley GJ, Fryirs KA. Geomorphology and river management: applications of the river styles framework. John Wiley and Sons: Hoboken. 2013.

[20] Wegscheider B, Linnansaari T, Monk WA, Curry RA. Linking fish assemblages to hydro-morphological units in a large regulated river. Ecohydrology. 2020; 13: e2233.

[21] Yu Z, Zhang J, Zhao J, Peng W, Fu Y, Wang Q, et al. A new method for calculating the downstream ecological flow of diversion-type small hydropower stations. Ecological Indicators. 2021; 125: 107530

[22] Kondolf GM. River restoration and meanders. Ecology and Society. 2006; 11: 42

[23] Gibling MR, Davies NS. Palaeozoic landscapes shaped by plant evolution. Nature Geoscience. 2012; 5: 99-105.

[24] Carvalho Carneiro de Mendonça B, Mao L, Belletti B. Spatial scale determines how the morphological diversity relates with river biological diversity. Evidence from a mountain river in the central Chilean Andes. Geomorphology. 2021; 372: 107447.

[25] Zhou X, Liu J, Song H, Qiu Y, Shi H. Estimation of Heterotrophic Biokinetic Parameters in Wastewater Biofilms from Oxygen Concentration Profiles by Microelectrode. Environmental Engineering Science. 2012; 29: 466-471.

[26] Wang R, Zhang Q, Zhang Y, Shi H, Nguyen KT, Zhou X. Unconventional Split Aptamers Cleaved at Functionally Essential Sites Preserve Biorecognition Capability. Analytical Chemistry. 2019; 91: 15811-15817.

[27] Hauer C, Unfer G, Holzmann H, Schmutz S, Habersack H. The impact of discharge change on physical instream habitats and its response to river morphology. Climatic Change. 2013; 116: 827-850.

[28] Wang H, Dong Z, Zhao J, Zhang J. Review on geomorphological heterogeneity of meandering river and its ecological significance. Water Resources Protection. 2015; 31: 81-85.

[29] Chung SJ, Ahn HK, Im DK. Analysis of aquatic physical habitat of channel connected pool using River2D, Korea. In Proceedings of the Korea Water Resources Association Conference. Korea Water Resources Association. 2009; 2083-2087.

[30] Mouton AM, Schneider M, Depestele J, Goethals PLM, De Pauw N. Fish habitat modelling as a tool for river management. Ecological Engineering. 2007; 29: 305-315.

[31] Macura V, Škrinár A, Kaluz K, Jalčovíková M, Škrovinová M. Influence of the morphological and hydraulic characteristics of mountain streams on fish habitat suitability curves. River Research and Applications. 2012; 28: 1161-1178.

[32] Liu L, Shan D, Zhou X, Shi H, Song B, Falke F, et al. TriPleX ${ }^{\mathrm{TM}}$ waveguide-based fluorescence biosensor for multichannel environmental contaminants detection. Biosensors and Bioelectronics. 2018; 106: 117-121.

[33] Liu L, Zhou X, Wilkinson JS, Hua P, Song B, Shi H. Integrated optical waveguide-based fluorescent immunosensor for fast and 
sensitive detection of microcystin-LR in lakes: Optimization and Analysis. Scientific Reports. 2017; 7: 3655.

[34] Zhu L, Zhou X, Shi H. A potentiometric cobalt-based phosphate sensor based on screen-printing technology. Frontiers of Environmental Science \& Engineering. 2014; 8: 945-951.

[35] Camporeale C, Ridolfi L. Interplay among river meandering, discharge stochasticity and riparian vegetation. Journal of Hydrology. 2010; 382: 138-144.

[36] Parker G, Shimizu Y, Wilkerson GV, Eke EC, Abad JD, Lauer $\mathrm{JW}$, et al. A new framework for modeling the migration of meandering rivers. Earth Surface Processes and Landforms. 2011; 36: $70-86$. 